\title{
Relevance, impact and academic spin
}

\author{
Neil Winterton
}

Published online: 1 July 2010

(C) Springer-Verlag 2010

Ideally, collective judgements about the development of cleaner technologies should be based on a complete and objective assessment of all the relevant and well-founded evidence. In reality, of course, this will not be possible as the evidence will be partial and incomplete and any assessment of it will be skewed by the interests, motivations and perspectives of those doing the assessing. Increasingly important to governmental, institutional and business decision-making in the transition to more sustainable ways of living are the attitudes of the wider public and their expression through the political process, informed, influenced or determined (take your pick) by the press, radio, television and the internet. While these influences are not wholly negative, the methods of the media increasingly affect the way science is published, promoted and presented.

I am not primarily concerned with the more obvious and egregious instances, such as the use of the media to make early disclosure of (non-peer-reviewed) experimental results that point to some major scientific breakthrough or matter of great social importance. The use of a press conference to present data from Pons (University of Utah) and Fleischmann (University of Southampton) believed to provide evidence of the phenomenon called 'cold-fusion' was followed by a major scientific debate that centred not just on the observations and their interpretation, but on the appropriateness of pre-empting the standard procedures of manuscript submission and peer-review. This was science in its proper self-correcting mode.

N. Winterton $(\bowtie)$

Department of Chemistry, University of Liverpool,

Liverpool L69 7ZD, UK

e-mail: N.Winterton@liverpool.ac.uk
Nor am I primarily concerned with 'Climategate' (nor even its sequel, 'Glaciergate'). The Intergovernmental Panel on Climate Change (IPCC 2007) has compiled and presented various summaries of the current (imperfect) state of knowledge that have been broadly accepted by fellow scientists (not, of course, without well-founded criticism and open-minded scepticism). This success is all the more remarkable because of the powerful intellects (I will not say inflated egos!) and heavy-weight disputation that characterise scientific discourse even in a single discipline, let alone across and between so many disciplines concerned with highly complex questions. Attempts to undermine these efforts prior to the UN climate change conference in Copenhagen in December 2009 led to 'Climategate', the media furore resulting from the theft and publication of e-mails and other material from the University of East Anglia Climate Research Unit. Increased scepticism of the lay public towards evidence for man-made impact on the world's climate appears to have resulted. My own view is that such scepticism is likely to be temporary (and unlikely to turn to scepticism's more virulent and destructive cousin, denialism), if a balanced view of the scientific evidence continues to be provided. There may, indeed, be some positive benefits from this affair: it may serve to underline, first that scientists are human after all, and second that important uncertainties in aspects of climate change science and its possible consequences (highlighted by sceptics) do remain to be resolved (Schiermeier 2010). Much of the criticism of the scientists concerned exploited the use of the word 'trick' to characterise a means of presenting data. In a scientific context, 'trick' is often used to describe a clever means of resolving a technical problem and does not have the pejorative meaning, used more widely, that of an underhand and deceitful action. That much of the Climategate controversy revolved around something as seemingly 
trivial underlines the importance of checking, when a word or term takes on such critical significance, whether it has a special meaning different from its more general usage. This cries out for more scientifically-aware journalists and more media-savvy scientists.

There are many contemporary examples of the uneasy relationship between journalism and science that have distorted public attitudes. Further twists arise when such controversies are caught up in electoral politics with, occasionally, unexpected outcomes. Such was the case, recently, in the UK. (土)-1-(4-methylphenyl)-2-methylaminopropan-1-one (known as mephedrone) has found use as a recreational drug. The death of two young people in Scunthorpe, Lincolnshire was reported at the time to be associated with the consumption of (the then legally available) mephedrone. This led to a clamour for its control, with media criticism of the then government for its slowness in responding to the problem of so-called 'legal highs'. Under media and political pressure, and facing imminent re-election, the government moved to regulate mephedrone, making its sale a criminal offence, despite conflicting input from specialists. Ironically, it was later confirmed that the two deaths could not be associated with mephedrone as no evidence for its presence was found on post-mortem examination. Here, we have a journalistically attractive story, one that was 'spun' to embarrass a government that some newspapers did not like, in the run up to a general election. However, the entire basis of the story was factually incorrect, as waiting for the coroner's report would have established.

There is a more general (parenthetical) point at issue here that concerns the relationship between science and government. The mephedrone story came after a longrunning and acrimonious argument between the government and its scientific advisors on the control of drugs [the Advisory Council on the Misuse of Drugs (ACMD)] that led, in November 2009, to the dismissal of the ACMD's chairman, Professor David Nutt, a respected expert on addiction, and to the resignation of other Council members. Nutt was accused, following a scholarly presentation, of campaigning against government policy while also being a government advisor. The issue raised broader questions concerning the relationship between government and the independent scientific expert advice it relies on (Winston Churchill famously and pithily remarked that scientists 'should be on tap, not on top'). Attempts to reconcile and codify (for both government ministers and advising scientists) the different roles of government in exercising and taking responsibility for political decision-making and scientists in providing evidence-based advice to aid such decision-making themselves have led to yet further (unresolved) debate. The context and direction of such debate may change yet again with the advent of a new UK government of a different political hue from the old one.
A rather different take on science and the media is exemplified when an organisation purposely sets out, selectively, to use what purports to be scientific data to promote a product or a point of view. Here, the responsibilities (in my view) rest squarely with the journalist, editor and media proprietor. Such instances are far too prevalent, as the excellent and very readable book, Bad Science, by Ben Goldacre (a medical doctor in general practice) (Goldacre 2008) illustrates. Ben Goldacre also writes a weekly column of the same name in the Saturday edition of the UK daily newspaper the Guardian, a welcome (and all too rare) instance of mainstream journalism policing its own. For example, a very recent column (Goldacre 2010) took to task a fellow journalist, writing in the Guardian's sister Sunday newspaper, the Observer, for suggesting that data from a study [published in the American Journal of Clinical Nutrition (McNamara et al. 2010)] of the effect of a dietary supplement on cortical activity in a group of 339 year-old boys (including 10 who received a placebo) was evidence to suggest that taking the supplement would lead to improvements in school performance and behaviour. In a related instance, another journalist, Simon Singh, suggested (also in the Guardian) that treatments recommended by the British Chiropractic Association were 'bogus'. This led not to the resolution of the dispute on the basis of the evidence, but to a legal action (recently dropped) against Singh for libel. The costs to defendants in such cases are likely to have a dampening effect on expressions of opinion in similar circumstances. This has led to calls for changes in the UK's libel laws (also affected by the change in the UK government). There is an evident overlap of mutual interests here between journalists and scientists in defending free speech, so it is refreshing that organizations such as Index on Censorship and Sense about Science are working together. Perhaps more of us should get involved.

However, the main concern I wish to focus on is more pervasive and more insidious. It is caught up with pressures (from funding agencies, governments and academic institutions) to demonstrate science's 'relevance' and its 'impact'. In seeking to justify its research and to tout the potential benefits of it both to scientific peers, funding agencies and the wider public, is there a danger that academic (as opposed to journalistic) spin ends up conflating scientific relevance with technological impact? Relevance and impact are two words (like 'sustainable' and 'development') whose meanings are too elastic for precise and agreed definition. Working at a UK university, I am subject to the pressures of the Research Assessment Exercise. Because the RAE is used by those disbursing infrastructure funding at the agency, institution and departmental levels great importance is attached to its outcome by academic and administrative staff, alike. Being responsible for the organisation and assembly of my own Department's 
submission to the most recent exercise, RAE 2008, I spent much of the previous four years encouraging my colleagues to consider more consciously where they chose to publish their scientific work [as, for those not familiar with the process, an assessment is made of the 'quality' and 'impact' of the research output of the staff included in the return (represented by four papers ('outputs') selected by each member of staff)]. The view taken by the RAE panel of 'quality' of these outputs determines, in the case of Chemistry, some $60 \%$ of the profile by which the submission is assessed. My role was to encourage publication in journals with high impact factors, particularly in leading science journals, such as Nature and Science. The Department excelled itself, increasing the proportion of returned outputs in journals with impact factors of $>7$ from 14 to $42 \%$. More papers also appeared in Nature (IF 31.434) and Science (IF 28.103). Here, we have a special meaning of the term impact. The 'Impact Factor' of a journal represents the average number of citations (in a particular 12 month period) per paper published in that journal in the previous 2 years (Thomson Reuters 2010). When, subsequently, I heard a very eminent academic (a theoretical physicist) refer in a seminar to Nature and Science as the 'popular press', I was, as you can imagine, brought up short. While there may have been a bit of academic snootiness about his comment, I think I see what he means; particularly, the increased use of news and views items about the content of the journals. A similar manifestation can be found in the increasing categorisation of some papers as 'hot' (dangerously flattering to the authors!), even before they are published and the rest of us (particularly those capable of exercising informed and critical judgement about the contribution) have a chance to read them. Authors of 'hot' papers can also pay to have their work featured on the cover of some journals. This is all getting very close to a sort of manufactured impact.

The danger is that those who write scientific papers, now more than ever, have an interest in seeing their work promoted rather than waiting for the judgement of, and esteem engendered amongst, those peers who subsequently read about it. On the other hand, it has to be said, so many advances in science are in disciplines about which, individually, we have but the dimmest of awareness. Making these papers 'accessible' by having them translated for us by an expert is, therefore, no bad thing. Or, am I being too old-fashioned or naive in believing that a piece of science should stand on its own without the artificial boost given to it by its publishers? There is probably a thesis or two to be written (sooner better than later) by historians of science to provide an analysis of the longer-term impact of papers initially touted as 'hot' or otherwise considered worthy of drawing to our special attention.
However, we should not forget that science has always raised strong passions regarding what it does and the implications for society of what is learned. In 2009, we celebrated three important scientific anniversaries, the bicentennial of the birth of Charles Darwin and the sesquicentennials of the publication of Darwin's On the Origin of Species and the death of Alexander von Humboldt. Both Darwin and von Humboldt were famous at the time, both recognised as superb scientists who made major contributions to our understanding of the natural world. However, Darwin is much more widely known to today's general public associated with the barely dimmed echoes of the public outrage that surrounded Darwin's work particularly among the religious establishment. The discussion of the societal impact of research and the conflict and debate to which ensuing controversies gives rise, is therefore not new. Neither are the importance of good science communication, enhanced scientific literacy and improved public understanding of science.

Yet it is possible to discern some differences between then and now that arise from changes in the nature, motivation and application of scientific research and the compressing of, and the dissolution of the barriers between, the different stages of research: its execution; its communication to scientific peers, its availability to the broader community comment on its significance and implication and its exploitation, application and consequence. Such supporting commentaries at least explain the basis of leading-edge scientific developments in ever-narrowing scientific specialities to the scientifically literate non-specialist. It also makes more accessible such advances to those with less understanding. The only down-side is if this is then used in ways that are not consistent with normal scientific standards and is used in a partial, biased or selective way. Whether or not one sees this as a 'good' thing in ensuring public accountability of science and scientists or a 'bad' thing in bringing about ill-informed comment from those with axes to grind is immaterial: this is the way it currently is.

Consideration of the issue of the presentation of science in the media raises questions regarding the relationship between journalists and scientists. The characteristics that best describe the separate roles of these two professions also define the difficulties of their relationship and the source of conflict between them: the need, on the one hand, for immediate, clear and unequivocal statements and, on the other, the importance of considered, deeply argued and qualified statements. However, the best interests of the wider society require them both to seek a better way of working, recognising and reconciling their differing responsibilities. Neither, however, should assume an automatic right to have their position considered pre-eminent under all circumstances. 
Scientists, with significant results to report, generally have announced their results in an understated manner quite at odds with the typical journalistic style (at least in their written scientific contributions). For instance, about 50 years ago, Watson and Crick (1953) began their famous double-helix paper in Nature with the following paragraph: 'We wish to suggest a structure for the salt of deoxyribose nucleic acid (D.N.A.). This structure has novel features which are of considerable biological interest.' There was no accompanying commentary or news item linked with this communication (or the associated communications from Maurice Wilkins and Rosalind Franklin). One only has to read James Watson's personal account (Watson 1968) of the discovery (including the competition with Linus Pauling) to understand the distance between the sober tones of 'it has not escaped our notice that the specific pairing we have postulated immediately suggests a possible copying mechanism for the genetic material' with the excited post-Eureka announcement by Francis Crick in the Eagle pub in Cambridge that they had discovered 'the secret of life'. On the other hand, reflecting the more modern methods of research and communication, one of the first papers to describe the sequencing of the human genome (International Human Genome Sequencing Consortium 2001) was accompanied in the same issue of Nature (in addition to ten supporting scientific papers) by a cover picture, two editorials, seven news and views articles, thirteen analyses, as well as a review of a book describing the race between two competing research groups, one public and the other private. Underlining my earlier point, an article also appeared (Judson 2001) highlighting the great care that needs to be exercised to be precise about technical terms used and their meaning.

A similar care is needed when using, in the context of the development of cleaner technologies, the terms relevance and impact, particularly when presenting or discussing the results of scientific work. There is a need clearly to delineate between two different but related things: first, the particular societal, industrial or environmental problem that a piece of research is seeking to understand or explore (the 'relevance') and second, the likelihood that (and the degree to which) it will have a benefit (whether direct or indirect, immediate or distant) in the realization of a technological development (the 'impact').

Since there is now a conscious effort to build the expectation of delivery of impact into scientific papers (particularly relating to sustainable development), there is a temptation to claim such an impact even when the gap between the research outcome presented and its full scale application is extremely wide. Giving in to this temptation (or, to permit someone else, such as a journal editor or a University press office to do so) may be understandable in terms of career development, RAE performance or raising the public profile of an area of work. However, it can distort the processes of idea exchange across disciplines and raise unwarranted expectations about the imminence of new technological developments. Our efforts to increase the use of renewable feedstocks in chemicals production or energy or fuel generation require a hard-nosed awareness of the thermodynamic, economic, societal and practical constraints under which new technologies will have to operate. It is often difficult (sometimes because of commercial confidentiality or intellectual property reasons) to get a realistic perspective on the state of development of a technology, whether it is so-called zero-emission automobiles, ethanol from crops, biodiesel from microalgae or the assembly of biorefineries to replace oil refineries. The way these important developments are highlighted, both in the papers themselves and associated commentaries, often focuses excessively on the positive optimistic aspects, when a more sober assessment of the costs, difficulties and timescales of what is required to bring a scientific development to full-scale realisation is needed instead [even if the 'impact' is less and more distant than we (or our press offices) would like].

The essential message is one of maintaining the ethos of science regarding our respect for evidence and the objective and reasoned presentation of its significance. Part of this is a preparedness to address all the evidence, even that with which we might disagree or which is used by those who oppose our points of view. It is not an accident that Mike Hulme, in the frontispiece to his excellent book Why We Disagree about Climate Change (Hulme 2009), quotes Jonathan Haidt (from his book The Happiness Hypothesis: Finding Modern Truth in Ancient Wisdom) that 'A good place to look for wisdom ... is where you least expect to find it: in the minds of your opponents'. The complexities of the challenges of the transition to more sustainable technology require those engaged in research to keep in mind the technical and economic challenges that must be met and to understand and take account of views which may differ from their own. For instance, those carrying out research of relevance to the development of biofuels may wish to consider their statements regarding the likely impact of their research in the light of the sobering book by Giampietro and Mayami (2009) entitled The Biofuel Delusion.

While it is tempting to raise awareness about things that concern us by feeding the media machine on the media's terms, previous experience tells us that, at some point, there is a conflict and it is usually science and scientists that come off the worse. In the longer term, particularly in the development of cleaner technology, this benefits no one. This is not the time for us to keep our heads down; instead, we should use them carefully, wisely and generously when we write about our work and that of others. 


\section{References}

Giampietro M, Mayami K (2009) The biofuel delusion: the fallacy of large scale agro-biofuel production. Earthscan, London

Goldacre B (2008) Bad science. HarperCollins Publishers, London

Goldacre B (2010) http://www.guardian.co.uk/commentisfree/2010/ jun/05/bad-science-omega3-fish-oil

Hulme M (2009) Why we disagree about climate change: understanding controversy, inaction and opportunity. Cambridge University Press, Cambridge

International Human Genome Sequencing Consortium (2001) Initial sequencing and analysis of the human genome. Nature 409: 860-921

IPCC (2007) http://www.ipcc.ch/publications_and_data/publications_ and_data.htm

Judson HF (2001) Talking about the genome. Nature 409:769
McNamara RK, Able J, Jandacek R, Rider T, Tso P, Eliassen JC, Alfieri D, Weber W, Jarvis K, DelBello MP, Strakowski SM, Adler CM (2010) Docosohexaenoic acid supplementation increases prefrontal cortex activation during sustained attention in healthy boys: a placebo-controlled, dose-ranging, functional magnetic resonance imaging study. Am J Clin Nutr 91: $1060-1067$

Schiermeier Q (2010) Climate: the real holes in climate science. Nature 463:284-287

Thomson Reuters (2010) http://thomsonreuters.com/products_services/ science/science_products/a-z/journal_citation_reports

Watson JD (1968) The double helix; a personal account of the discovery of the structure of DNA. Weidenfeld and Nicolson, London

Watson JD, Crick FHC (1953) Molecular structure of nucleic acids: a structure for deoxyribose nucleic acid. Nature 171:737-738 